\title{
Effect of Moisture Content on the Shear Behaviour of a Completely Decomposed Granite: An Experimental Study
}

\author{
Pan Liu $\left(\mathbb{D},{ }^{1}\right.$ Jinhong Lin, ${ }^{2}$ Yang Wang, ${ }^{2}$ and Xueqiang Yang $\mathbb{D}^{2}$ \\ ${ }^{1}$ Navigational Engineering Department, Guangzhou Maritime University, Guangzhou 510725, China \\ ${ }^{2}$ School of Civil and Transportation Engineering, Guangdong University of Technology, Guangzhou 510006, China \\ Correspondence should be addressed to Xueqiang Yang; xqyfls@126.com
}

Received 18 December 2020; Revised 16 January 2021; Accepted 14 March 2021; Published 23 March 2021

Academic Editor: Junhong Yuan

Copyright (C) 2021 Pan Liu et al. This is an open access article distributed under the Creative Commons Attribution License, which permits unrestricted use, distribution, and reproduction in any medium, provided the original work is properly cited.

To figure out the effect of moisture content on the shear behaviour of undisturbed completely decomposed granite (CDG) soil, a series of in situ and laboratory direct shear tests were carried out, under different normal stress and moisture contents. The test results showed that the increasing moisture content could obviously weaken the shear strength, cohesion, and frictional angle. Two linear equations were proposed for estimating the cohesion and the frictional angle at any moisture content in the field. The estimated strength parameters could be used for safety evaluation and/or engineering design of CDG cutting slope. The rate of reduction of the cohesion was much higher than that of the tangent value of frictional angle. Due to the disturbance of laboratory sample and size effect, the strength parameters obtained from the in situ test were a little bit higher than those from the laboratory test.

\section{Introduction}

Rainfall-induced landslide usually causes catastrophic disaster, for example, a slope in Shenzhen, China, failed after a heavy rainstorm and killed 78 people in 2015 [1]. The main reason for this kind of failure is that the soil mechanical properties decreased with the increasing water contents resulting from rainfall infiltration. The mechanical behaviour is seriously influenced by the moisture content both for undisturbed soil (usually encountered in cutting slope) and re-compacted soil (filled slope) [2,3]. In situ tests can directly show the mechanical behaviour of the soil in construction location. However, because of inconvenience and high cost, in situ tests are seldom carried out. Instead, laboratory tests, i.e., direct shear test and triaxial test, are usually performed to obtain the mechanical parameters used for the safety evaluation [4-6]. However, due to the disturbance of soil specimen during sampling, transportation, and installation, the mechanical parameters obtained from the lab test are usually lower than those in the field, which would result in the rise of the inaccuracy of numerical simulation and the difficulty to do the safety evaluation $[7,8]$.

Completely decomposed granite (CDG), as a main component of weathered granitic crust, is widely distributed in Malaysia, Brazil, South Korea, and especially Southeast China [9-11]. Due to the humid and warm climate in these areas, the thickness of CDG layer is usually in the range of $10 \mathrm{~m}-30 \mathrm{~m}$. So, CDG is one of the most common soils encountered and is usually used as filled geomaterial. In Hong Kong, lots of artificial slopes were filled by re-compacted CDG soils in 1970s, and because of the lack effort of compaction during construction, the compaction degrees of these slopes were very low (less than $80 \%)[12,13]$. When the loose soils encountered water, the shear strength decreased dramatically, which resulted in many failures during or soon after heavy rainstorm every year. The shear strength can be described by the 
Mohr-Coulomb criterion with two material parameters, namely, the cohesion $c$ and the internal frictional angle $\varphi$ as follows:

$$
\tau_{f}=c+\sigma \tan \varphi \text {, }
$$

where $\tau_{f}$ is the shear strength and $\sigma$ is the normal stress at the failure plane. To find out the influence of water content on the shear strength of loose compacted CDG, a series of laboratory direct shear tests were carried out, and the strength parameters $c$ and $\varphi$ were obtained by linear fitting, which could be then adopted for engineering design $[14,15]$.

In Southeast China, undisturbed CDG was encountered in many cutting slopes. The mechanical behaviour of this undisturbed soil has been studied at laboratory in recent years [16-18], but seldom researched in the field. In this study, to investigate the influence of moisture content on the shear mechanical behaviour of undisturbed CDG, both in situ direct shear tests and laboratory tests were performed with various normal stresses and water contents. The strength parameters $c$ and $\varphi$ were obtained by linear fitting of test data.

\section{Test Material and Procedure}

The in situ direct shear tests of undisturbed CDG soil were conducted on a cutting slope located at Huizhou city, China, as illustrated in Figure 1. The soil was weathered from the Late Yanshanian granite according to the geological report. From visual inspection, the parent rock has been completely decomposed, but some of the original fabric and texture could be observed clearly. The soil could be easily crumbed by hand, and it was mainly brown and gray in color with some flesh red patches. According to the classification system proposed by Geotechnical Engineering Office [19], the soil could be classified as completely decomposed granite (Grade V).

Basic property tests were performed in accordance with BS1377 (British Standards Institution, 1990) [20], including specific gravity tests, Atterberg limit tests, sieving, and hydrometer analysis. The properties of the soil are shown in Table 1, and the particle size distribution curve is illustrated in Figure 2. The soil can be classified as sandy clay (CL) according to the Unified Soil Classification System (ASTM 2017) [21].

The in situ direct shear tests comprised of three series, for which the moisture contents were different. One series tests were carried out right after the soil block samples had been exposed to sunshine by half month, and so the moisture contents were lower than the natural one (Table 2, si1 to si6). The other series was performed the next day after a heavy rainstorm, as the samples reached moisture equilibrium, and the water contents were higher than the natural one (Table 2, si7 to si11). The third series tests were performed immediately after the block samples were created, and the moisture contents were natural (Table 2, si12 to si16). The soil taken from shear band of each block sample was used to measure the moisture content when the shearing was finished. The procedure of the in situ tests is described as follows:
(1) Preparation of block samples: three test pits were excavated at the construction site, for which the depths were about $1.5 \mathrm{~m}$. In each pit, several block samples were formed by using pickaxe and saw to cut the ground soil to the sizes of $60 \mathrm{~cm}$ length $\times 50 \mathrm{~cm}$ width $\times 50 \mathrm{~cm}$ height, as shown in Figure 1. The samples in one pit were tested in dry condition and those in another pit were sheared in moist condition, and the soils in the third pit were tested in natural condition, which correspond to the three series in situ tests as mentioned previously.

(2) Installation of loading device: the reactive force system was then set up, which included several cuboid stone blocks, two shape steels, and two jacks, as shown in Figure 3. Then, the shear box was assembled, which consisted of four steel plates and several bolts. The steel plates had the thickness of $20 \mathrm{~mm}$ to make sure enough stiffness so that the deformation of the box itself would be very small during the test. Then, four dial indicators were installed to measure the displacements of block sample, two for vertical displacement and the others for horizontal displacement. One jack was then placed on the top of the sample for applying normal force, and another jack was installed on the side to apply shear force. In order to let the normal force could be applied onto the block sample uniformly, a steel plate was put between the upper jack and the sample. A part of the test system is shown in Figure 4. As shown in Figure 4, the block sample was higher than the shear box. It was because that the sample was very difficult to be cut in the field. The high soil sample would not change the normal stress on the shear surface, so it would not affect the results of the tests.

(3) Loading procedure: the predetermined normal force was then applied on the sample by the upper jack. For each vertical load application, the vertical deformation of the sample was treated to be steady if the increment was less than $0.1 \mathrm{~mm}$ in 5 minutes. As the vertical displacement was stable, the shear force was applied by several grades until failure occurred. The shear force in the field test was not applied by constant rate of displacement, unlike laboratory test, and it was applied by constant force in each grade. In each grade, the horizontal and vertical displacements of the sample were measured. The shear force of each grade would not be applied until the displacements of upper grade remain steady. The normal force was controlled to be constant during shearing.

The samples for the laboratory test were obtained by pushing cutting ring into the ground soil at the bottom of pit, immediately after the in situ tests were finished, to make sure that the moisture contents of the ring samples were close to that of the in situ samples as possible. The size of ring sample was $6.18 \mathrm{~cm}$ diameter $\times 2 \mathrm{~cm}$ height. The moisture content of each ring sample was measured after the lab test. The details 


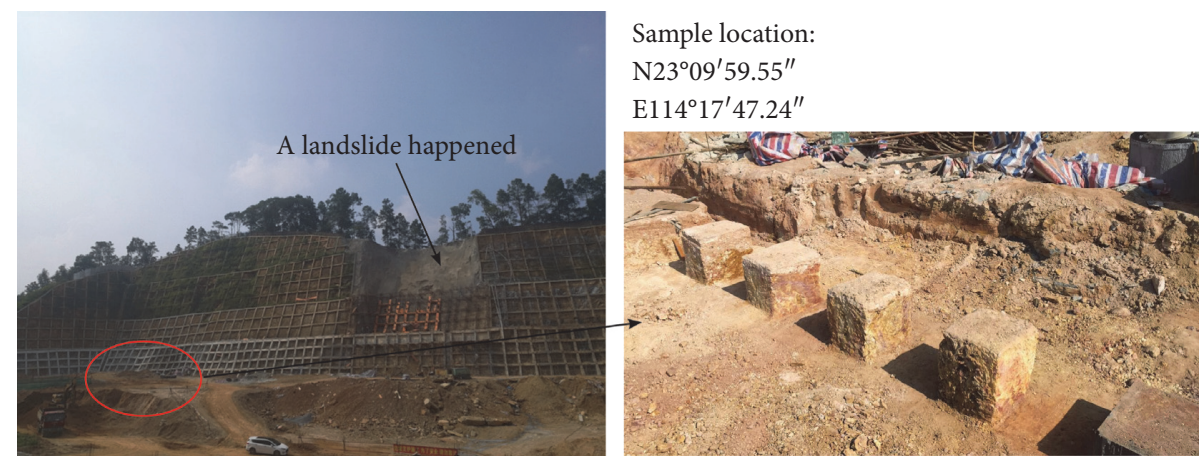

Figure 1: Sample location in Huizhou, China.

TABLE 1: Material properties of the CDG soil.

\begin{tabular}{lcccccccc}
\hline Soil type & \multicolumn{4}{c}{ Particle size } & & & & \\
& distribution (\%) & $G_{s}$ & Natural moisture content (\%) & Liquid limit (\%) & Plastic limit (\%) & Plastic index & USCS \\
& Sand & Silt & Clay & & & & & \\
\hline CDG & 48.6 & 45.4 & 6 & 2.57 & 8.23 & 30 & 19 & 11 \\
\hline
\end{tabular}

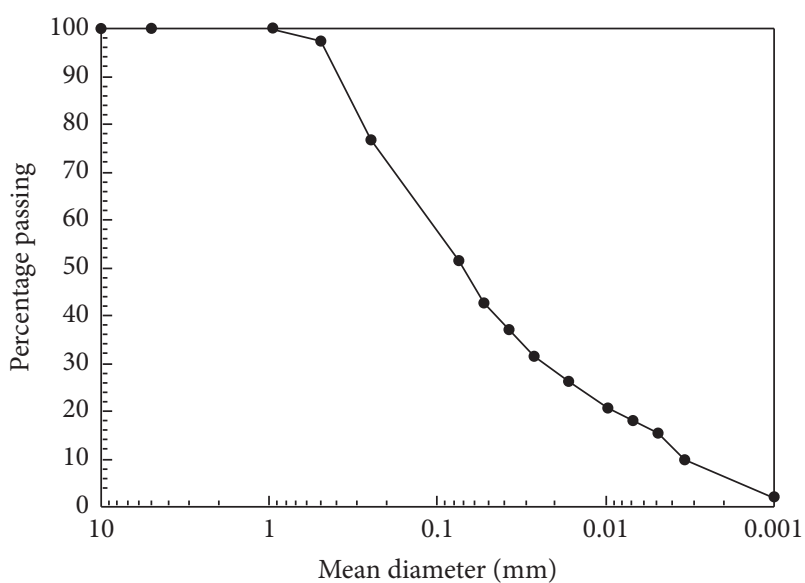

Figure 2: Particle size distribution curve of the CDG soil.

of in situ and laboratory tests are listed in Table 2. The in situ test in humid condition with the normal stress of $300 \mathrm{kPa}$ was terminated at the beginning of shearing because of a mechanical problem, so there were only five completed field tests in humid condition.

\section{Test Results and Discussion}

3.1. In Situ Test Results. The stress-strain curves of the undisturbed CDG under dry, humid, and natural conditions obtained from the in situ test are shown in Figures 5-7, respectively. The void ratio $e$ of each sample listed in the figures was measured before the test.

It can be seen that all the block samples showed strainsoften behaviour during shearing, despite different moisture contents. At the initial stage, the shear stress increased with the increasing shear displacements. The soil structure afforded the main resistance, until the peak shear stress was reached. Then, with the collapse of soil structure, the shear stress decreased rapidly with the shear displacement to a steady value. The residual shear stress was almost supplied by the friction which was dominated by the frictional angle of the soil and the normal stress $(\sigma \tan \varphi)$. In each condition, higher normal stress resulted in higher peak shear stress, except sample si4 ( $\sigma=150 \mathrm{kPa}$, Figure 5(a)), for which the peak stress would be expected to be higher than that of sample si3 $(\sigma=100 \mathrm{kPa})$. It can be noted that the void ratio of si4 was 0.584 , obviously higher than that of the other samples, which means the sample si4 had a lower density. That would result in a lower peak shear stress than si3, although its normal stress is higher. In this case, the influence of density on the peak shear stress was greater than the normal stress.

The vertical displacements of the soil samples are also shown in the figures. The upward displacement, which means dilatancy, is defined to be negative value. Under low normal stress, the soil showed strong dilatancy during shearing, and with the increase of the normal stress, the soil behaved to be contractive at the beginning and turned to be dilative at high strain. As expected, the soil tended to be contractive during all the shear process under high normal stress. In each moisture condition, the higher normal stress resulted in greater shear compression, except sample si4 which was thought to be a scatter. As mentioned earlier, the void ratio of si4 was higher than that of others, and the high $e$ resulted in an unexpected compression (Figure 5(b)). The curve of si4 was expected to lie between si3 and si5 if their void ratio were similar. However, the high void ratio of si4 meant that there existed more void which could be compressed during shearing than other samples. So, si4 showed a high compression, even that the normal stress was lower than si5. With the same normal stress, the vertical displacement at the end of shearing in the dry condition was always lower than that in the humid condition, showing more dilatancy. The increasing moisture content could increase the shear compression. 
Table 2: Details of the in situ and laboratory direct shear tests.

\begin{tabular}{|c|c|c|c|c|c|}
\hline Sample identification & Normal stress $(\mathrm{kPa})$ & Peak shear stress $(\mathrm{kPa})$ & Residual shear stress $(\mathrm{kPa})$ & Moisture content (\%) & Void ratio \\
\hline $\operatorname{sil}^{\mathrm{a}}$ & 0 & 60 & 12 & 3.23 & 0.563 \\
\hline si 2 & 50 & 140 & 53 & 4.64 & 0.531 \\
\hline si3 & 100 & 230 & 121 & 3.79 & 0.511 \\
\hline si 4 & 150 & 210 & 103 & 4.73 & 0.584 \\
\hline si5 & 200 & 309 & 216 & 3.95 & 0.562 \\
\hline si6 & 300 & 360 & 269 & 4.25 & 0.539 \\
\hline si7 & 0 & 35 & 18 & 19.62 & 0.529 \\
\hline si8 & 50 & 80 & 63 & 20.95 & 0.533 \\
\hline si9 & 100 & 95 & 60 & 21.29 & 0.505 \\
\hline $\operatorname{si10}$ & 150 & 145 & 111 & 19.36 & 0.561 \\
\hline $\operatorname{si1} 1$ & 200 & 180 & 150 & 20.84 & 0.554 \\
\hline si12 & 0 & 54 & 14 & 7.96 & 0.519 \\
\hline si13 & 50 & 125 & 55 & 8.14 & 0.531 \\
\hline sil4 & 100 & 175 & 85 & 8.99 & 0.550 \\
\hline si15 & 150 & 206 & 141 & 9.62 & 0.586 \\
\hline si16 & 200 & 238 & 179 & 8.31 & 0.542 \\
\hline la $12^{\mathrm{b}}$ & 50 & 94 & 38 & 1.49 & 0.607 \\
\hline la13 & 100 & 189 & 91 & 1.54 & 0.513 \\
\hline la14 & 150 & 225 & 113 & 1.26 & 0.533 \\
\hline la15 & 200 & 234 & 144 & 1.39 & 0.600 \\
\hline la16 & 50 & 69 & 38 & 20.08 & 0.519 \\
\hline la17 & 100 & 87 & 65 & 22.03 & 0.552 \\
\hline la18 & 150 & 139 & 85 & 19.34 & 0.463 \\
\hline la19 & 200 & 122 & 114 & 22.99 & 0.590 \\
\hline la20 & 50 & 102.9 & 40.3 & 7.16 & 0.524 \\
\hline la21 & 100 & 174.5 & 66.3 & 8.21 & 0.596 \\
\hline la22 & 150 & 200.1 & 116.1 & 7.95 & 0.557 \\
\hline la23 & 200 & 226.7 & 143.8 & 7.33 & 0.549 \\
\hline
\end{tabular}

${ }^{a}$ si means the in situ test; ${ }^{b}$ la means the laboratory test.

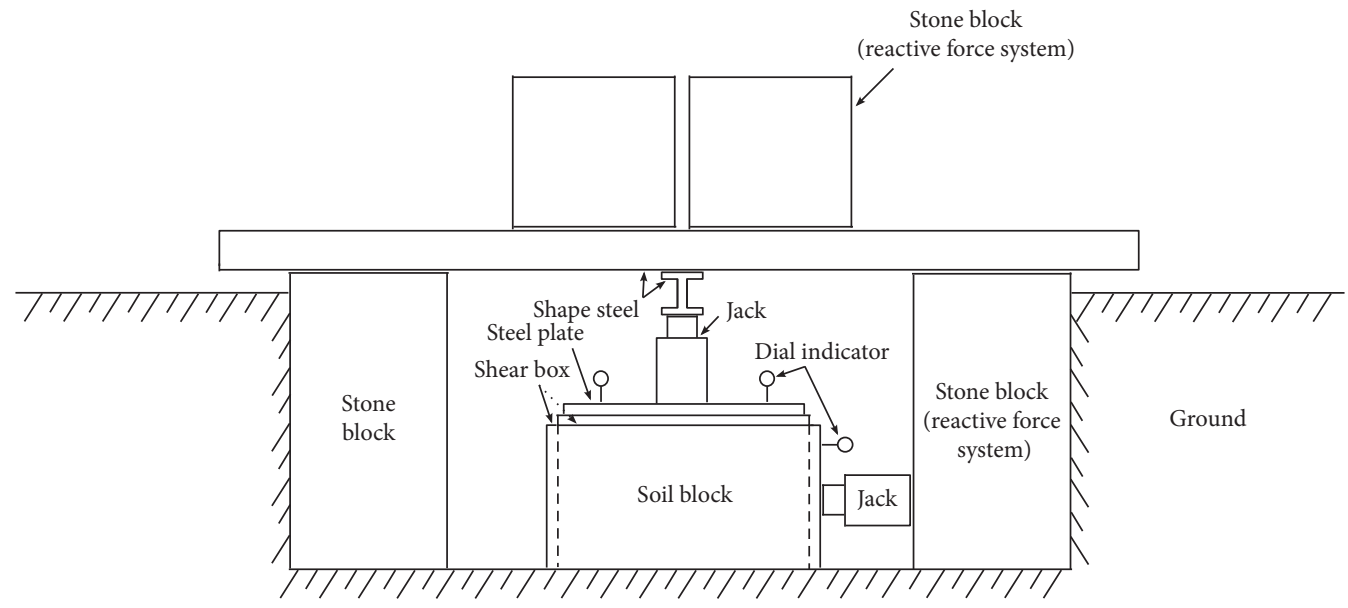

FIgURE 3: Illustration of the in situ direct shear test.

The test data of the peak and residual shear stress versus the normal stress of each in situ sample are illustrated in Figure 8. The stress data of the samples in natural condition are not illustrated for clarity. Linear fitting is used to obtain the strength parameters, and the equations are also given in the figure. From the fitted equations, the strength parameters from the in situ test can be obtained, as shown in Table 3.

In the in situ test, the cohesion and friction angle obtained in the dry condition were $88 \mathrm{kPa}$ and $44.2^{\circ}$, respectively. In the natural condition, for which the moisture content was a little higher than that of the dry condition, the cohesion and frictional angle were $70 \mathrm{kPa}$ and $41.9^{\circ}$. As the moisture content increased, in the humid condition, the peak shear stress with the same normal stress was obviously lower than that in the dry and natural conditions (Figure 8), and the cohesion and frictional angle were $36 \mathrm{kPa}$ and $35.4^{\circ}$. The strength parameters in different moisture contents are shown in Figure 9. It can be seen that both the cohesion and frictional angle decreased with the increasing moisture 


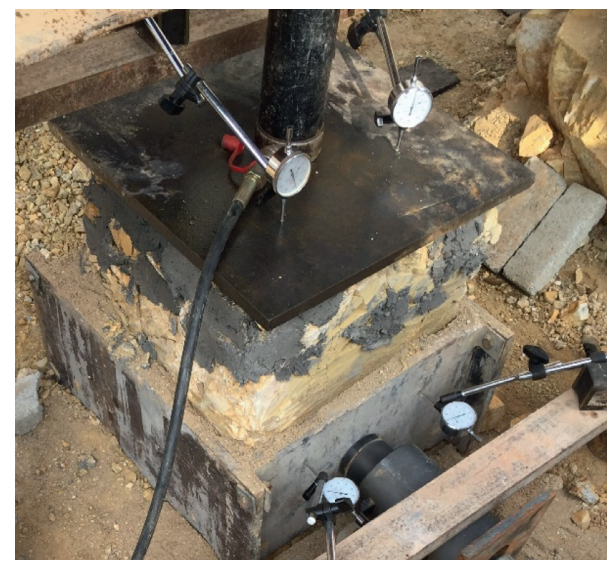

FIgURe 4: Picture of a part of the in situ test system.

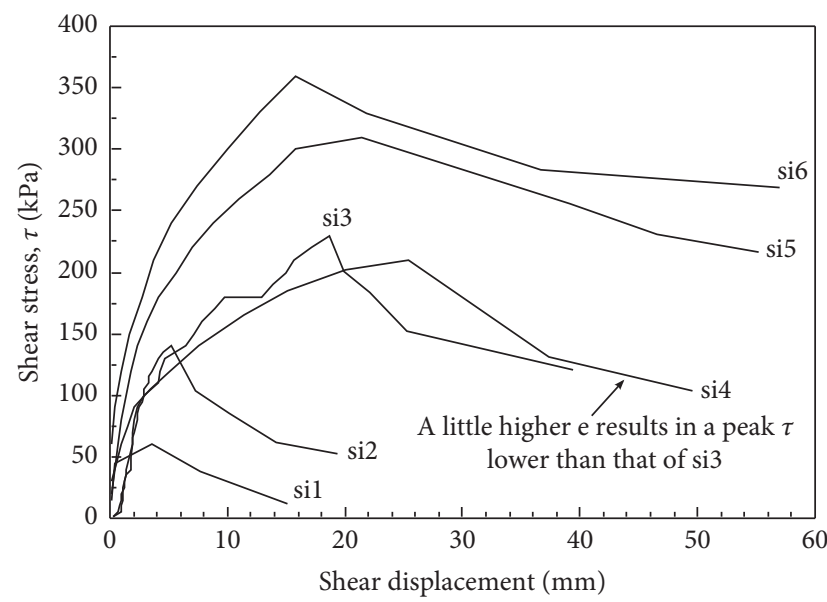

(a)

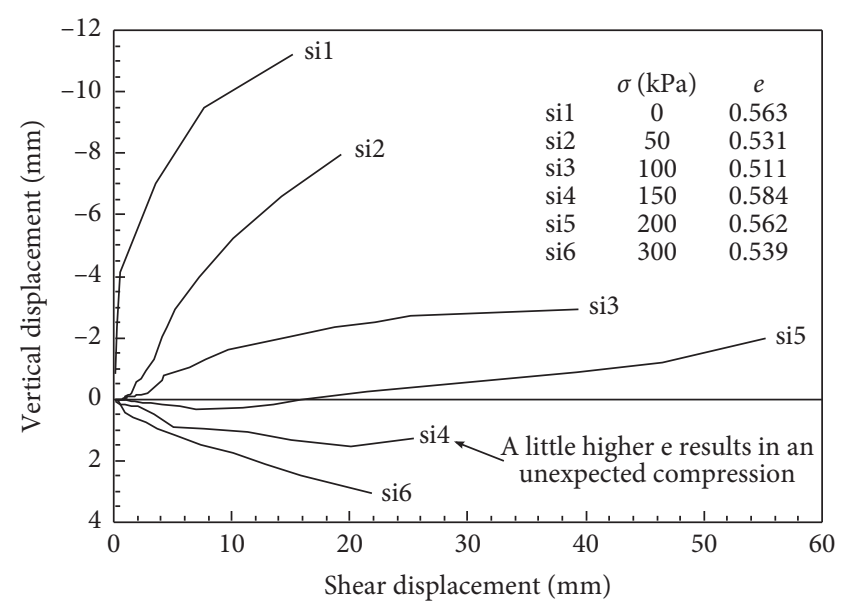

(b)

Figure 5: Data of the in situ direct shear tests under dry condition. (a) Shear stress versus shear displacement. (b) Vertical displacement versus shear displacement.

contents linearly. Besides, the rates of reduction of the cohesion and tangent value of frictional angle were 59\% and $27 \%$ as the moisture content changed from $4.1 \%$ (dry condition) to $20.4 \%$ (humid condition). The equations of the fitted lines for cohesion and frictional angle are listed as follows:

$$
\begin{aligned}
& c^{\prime}=-3.13 w+99, \\
& \varphi^{\prime}=-0.54 w+46,
\end{aligned}
$$

where $c^{\prime}(\mathrm{kPa})$ and $\varphi^{\prime}\left({ }^{\circ}\right)$ are the cohesion and the frictional angle at the moisture content of $w$. With the two equations, the cohesion and the frictional angle at any moisture content can be estimated for safety evaluation and/or engineering design of cutting slope of CDG soil.

3.2. Laboratory Test Results. The stress-strain curves of the undisturbed CDG in the dry, humid, and natural moisture conditions obtained from the laboratory test are shown in Figures $10-12$, respectively.
All the samples in the laboratory test showed the strainsoften behaviour, same as the block samples in the field test. In each humidity condition, the shear strength increased with normal stress, except sample la18 $(\sigma=150 \mathrm{kPa})$, for which the peak shear stress was obviously higher than that of sample la19 $(\sigma=200 \mathrm{kPa})$ because of its very low void ratio (high density). With the similar void ratios, the peak stress in dry condition was higher than that in humid condition under the same normal stress, which means the increasing moisture content can weaken the shear strength of the undisturbed CDG. Both in the dry and natural conditions, all the samples showed negative vertical displacements (dilatancy) at the end of the test. In the humid condition, with the increasing normal stress, the samples turned from dilative to contractive. Sample la17 $(\sigma=100 \mathrm{kPa})$ showed a little dilatancy during all the shear process, and the sample la19 $(\sigma=200 \mathrm{kPa})$ behaved to be contractive. It can be noted that the sample la18 $(\sigma=150 \mathrm{kPa})$ showed a strong dilatancy at the initial stage and trended to a negative value at the shear displacement of $7 \mathrm{~mm}$. The displacement curve of la18 was expected to lie between la17 and la19. However, the low void 


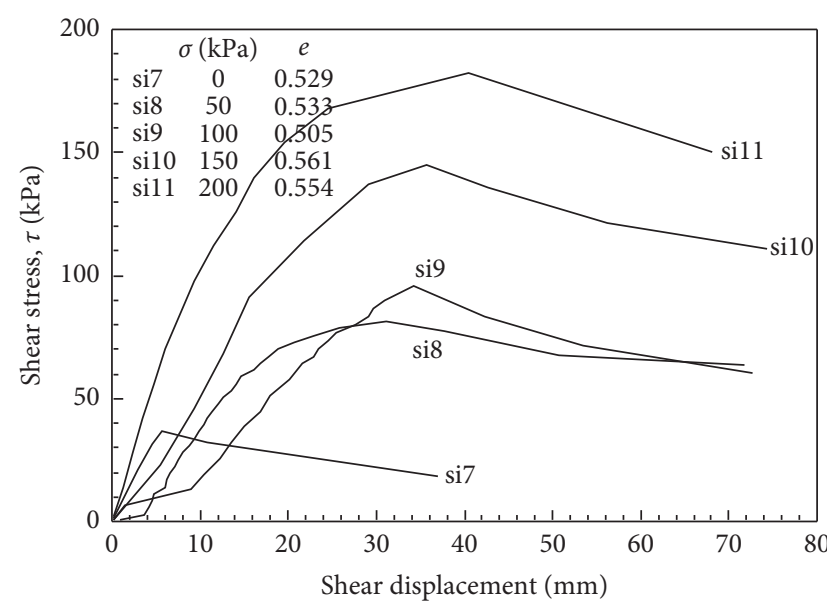

(a)

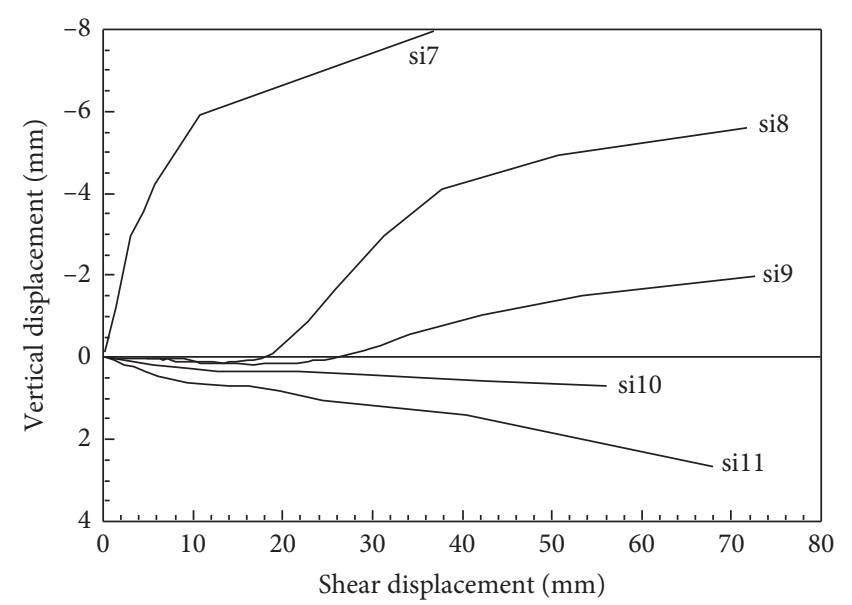

(b)

Figure 6: Data of the in situ direct shear tests under humid condition. (a) Shear stress versus shear displacement. (b) Vertical displacement versus shear displacement.

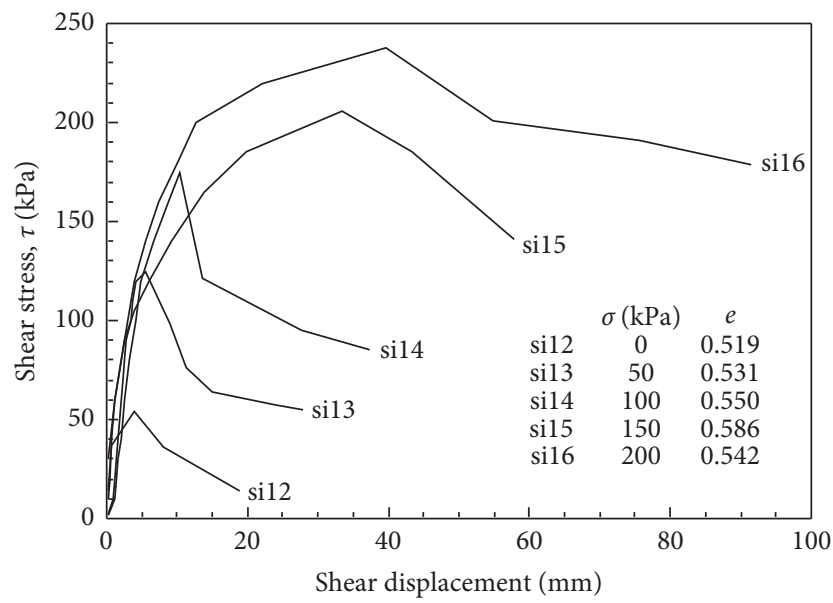

(a)

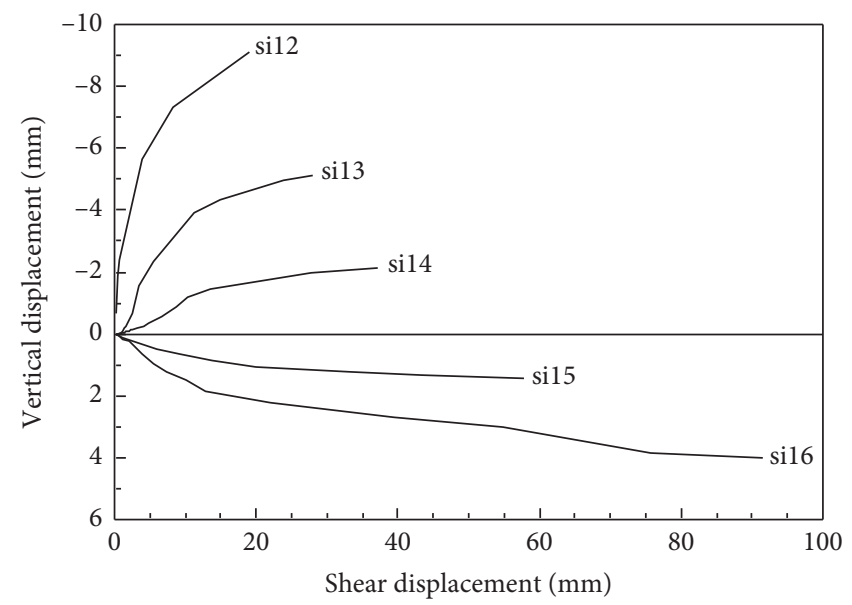

(b)

Figure 7: Data of the in situ direct shear tests under natural condition. (a) Shear stress versus shear displacement. (b) Vertical displacement versus shear displacement.

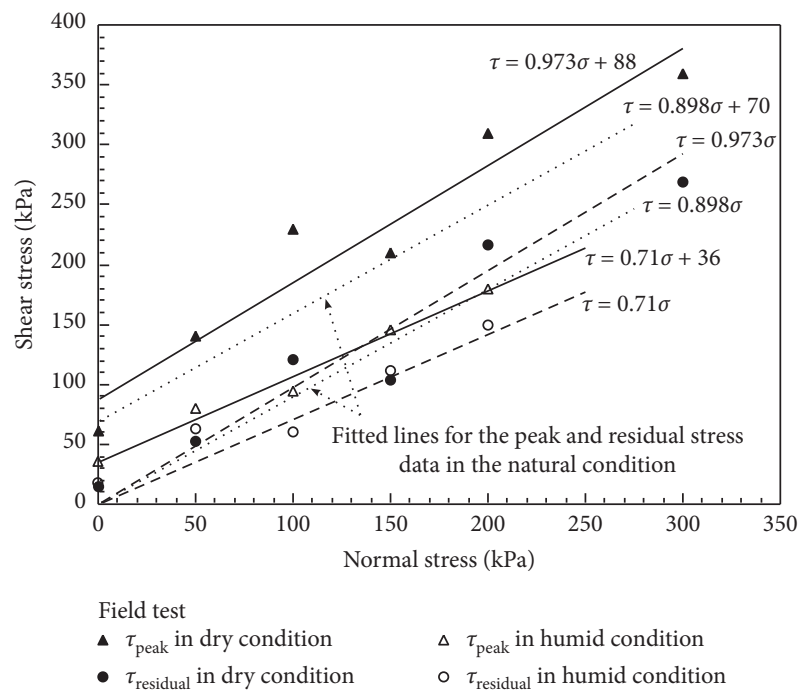

Figure 8: Test data and fitted lines of the in situ tests.
TABle 3: Strength parameters obtained from the in situ tests.

\begin{tabular}{lcc}
\hline Humidity condition & Cohesion, $c(\mathrm{kPa})$ & Frictional angle, $\varphi\left(^{\circ}\right)$ \\
\hline Dry & 88 & 44.2 \\
Natural & 70 & 41.9 \\
Humid & 36 & 35.4 \\
\hline
\end{tabular}

ratio, which means a high density, of this sample would result in a strongly dilative behaviour during shearing, and this strong dilatancy would result in a dramatic peak shear stress, as shown in Figure 11.

The test data of the peak and residual shear stress versus the normal stress of each laboratory test are illustrated in Figure 13, and the strength parameters obtained are shown in Table 4. The strength parameters obtained from the lab test in different moisture contents are shown in Figure 14.

The cohesion and frictional angle obtained from the laboratory tests were $85 \mathrm{kPa}$ and $37.1^{\circ}$ in the dry condition 


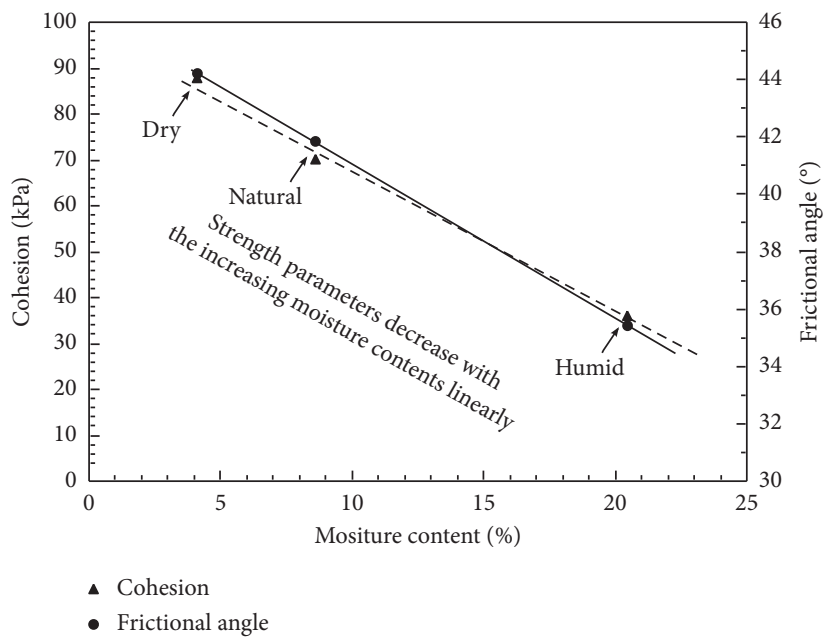

FIGURE 9: Strength parameters obtained from in situ test versus moisture content.

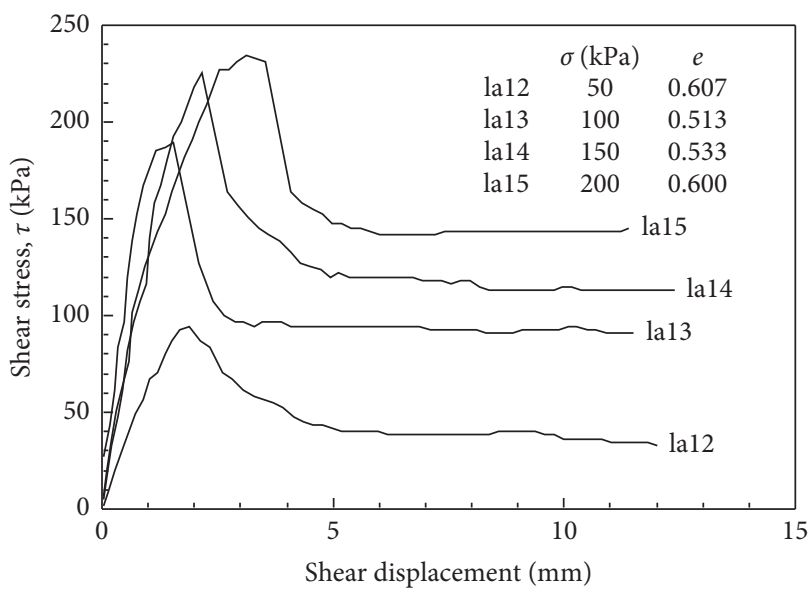

(a)

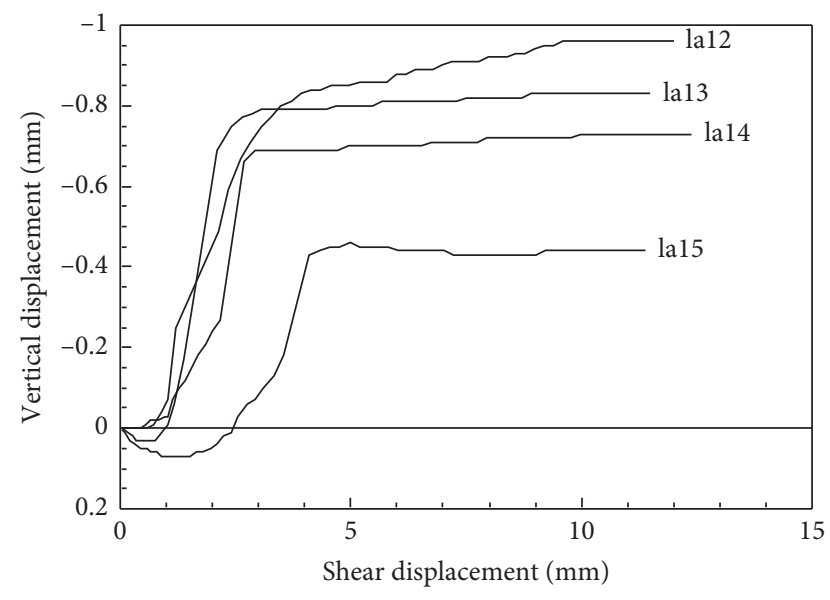

(b)

Figure 10: Data of the laboratory tests in dry condition. (a) Shear stress versus shear displacement. (b) Vertical displacement versus shear displacement.

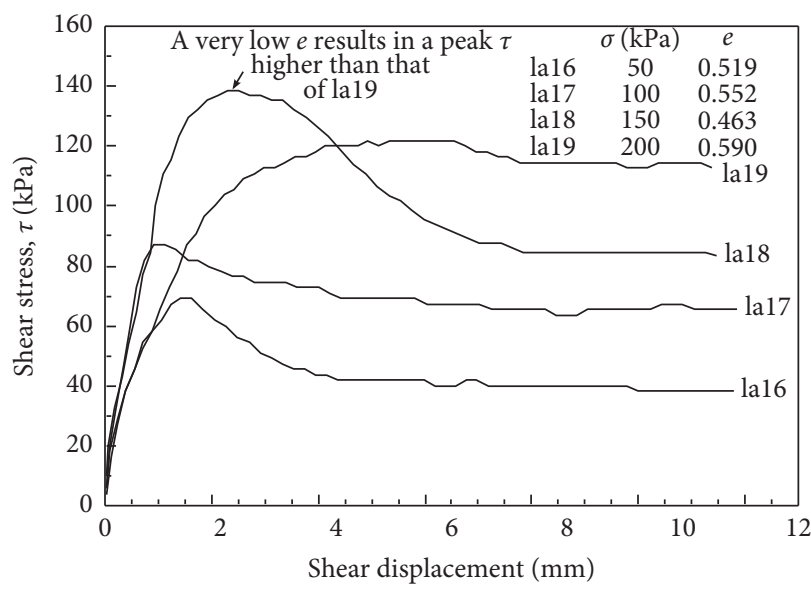

(a)

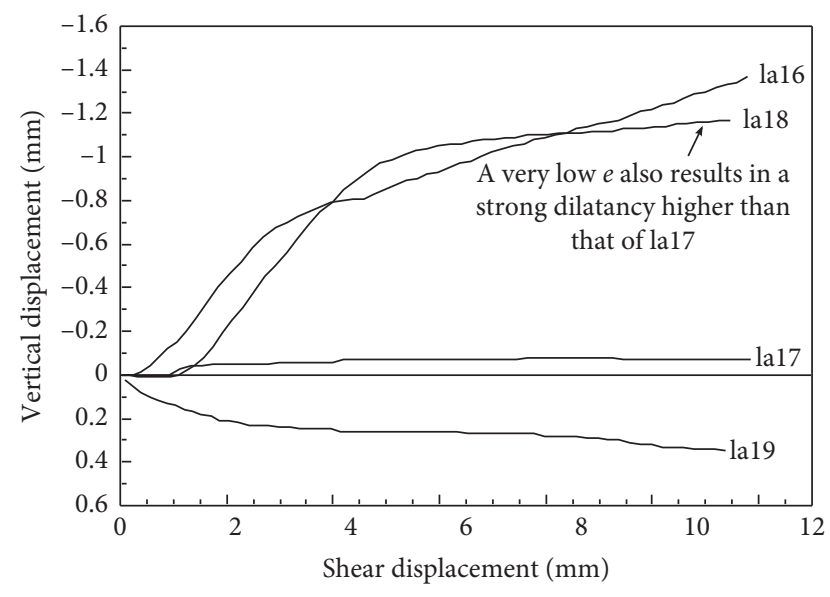

(b)

FIGURE 11: Data of the laboratory tests in humid condition. (a) Shear stress versus shear displacement. (b) Vertical displacement versus shear displacement. 


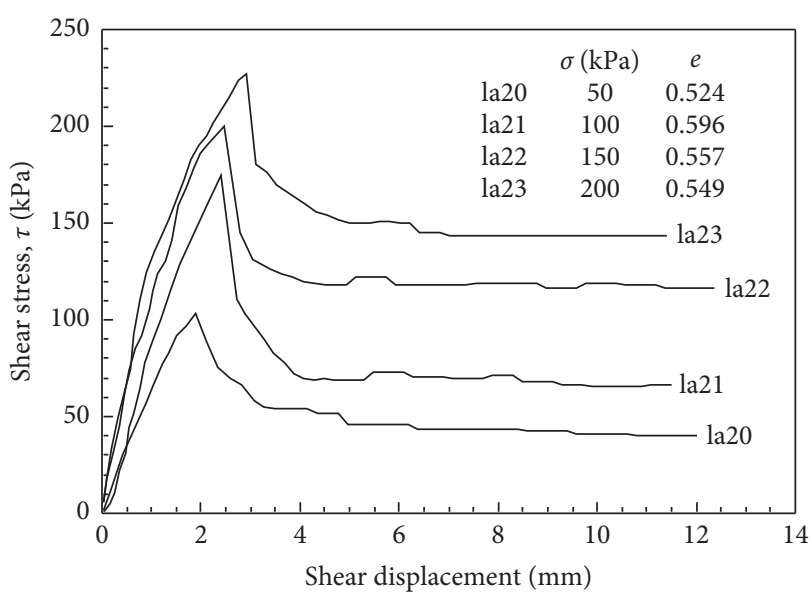

(a)

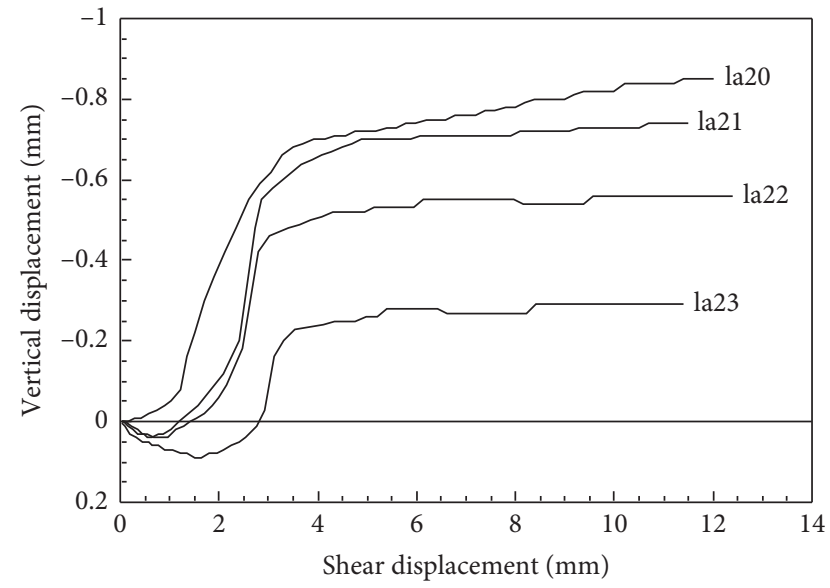

(b)

Figure 12: Data of the laboratory tests in natural condition. (a) Shear stress versus shear displacement. (b) Vertical displacement versus shear displacement.

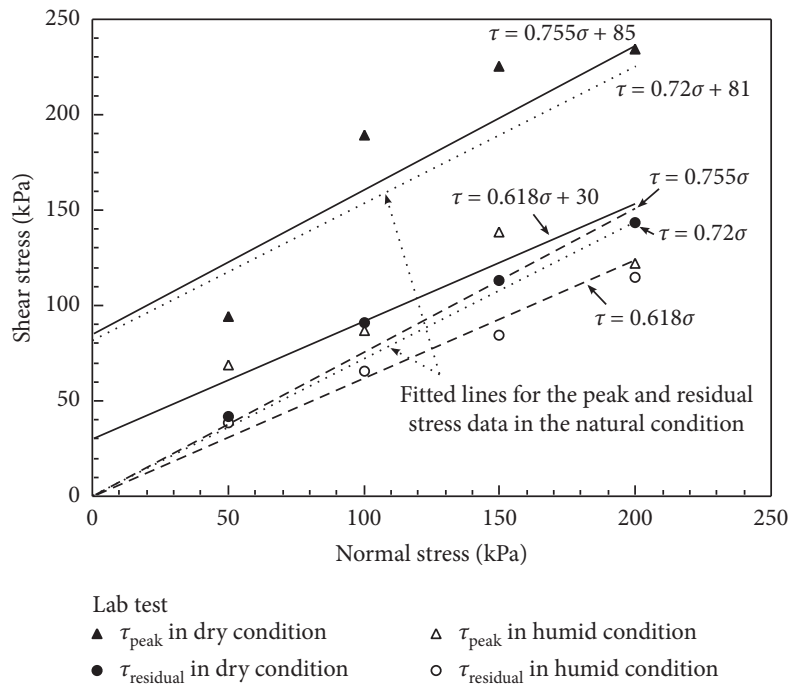

FIgURE 13: Test data and fitted lines of the laboratory tests.

TABLE 4: Strength parameters obtained from the laboratory tests.

\begin{tabular}{lcc}
\hline Humidity condition & Cohesion, $c(\mathrm{kPa})$ & Frictional angle, $\varphi\left(^{\circ}\right)$ \\
\hline Dry & 85 & 37.1 \\
Natural & 81 & 35.8 \\
Humid & 30 & 31.7
\end{tabular}

and decreased to $30 \mathrm{kPa}$ and $31.7^{\circ}$ in the humid condition. The rates of reduction of the cohesion and tangent value of frictional angle were 65\% and 18\%. As seen in Figure 14, both the cohesion and the frictional angle decreased with the increasing moisture content linearly, same as the field tests.

By comparing the strength parameters obtained from the in situ tests and the laboratory tests, it can be concluded that the strength parameters obtained from the in situ test were slightly higher than those from the laboratory test with similar moisture content. This was due to the reason that the disturbance during sampling, transportation, and installation would weaken the soil structure of the laboratory samples, and the size effect could also affect the shear strength. In both the in situ and laboratory tests, the moisture content could obviously influence the shear behaviour of the undisturbed CDG soil. Besides, the strength parameters, cohesion, and frictional angle decreased with the increasing moisture contents linearly. The rate of reduction of the cohesion was much higher than that of the tangent value of frictional angle, which meant that the bonds of undisturbed CDG were much easily influenced by the moisture content than the fabric. Further research is required to find out the mesoscopic mechanism for this behaviour. 


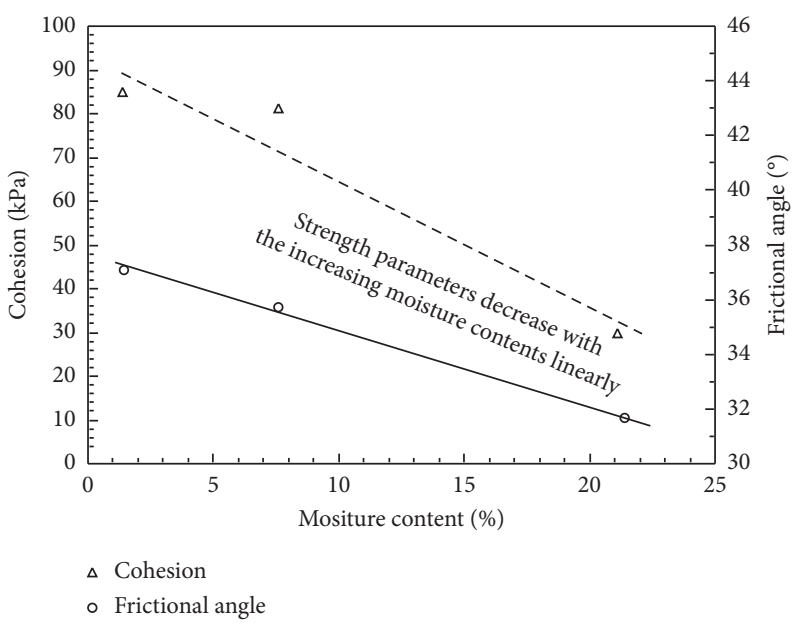

FiguRE 14: Strength parameters obtained from laboratory test versus moisture content.

\section{Conclusions}

This paper presents the test data and the interpretations on the shear strength characteristics of undisturbed CDG soil in its unsaturated state. Direct shear tests in field and laboratory were carried out with different moisture contents and normal stress. The following conclusions are drawn based on the study presented in the previous sections:

(1) The normal stress has a remarkable influence on the shear strength of undisturbed CDG. With similar void ratio, the higher normal stress would result in higher shear strength and more shear compression. However, sometimes a large difference in void ratio (density) could result in an unexpected shear behaviour.

(2) Moisture content plays an important role on the shear strength characteristic of undisturbed CDG. The increasing moisture content could obviously weaken the shear strength, the cohesion, and the frictional angle. Two linear equations were proposed for estimating the cohesion and the frictional angle at any moisture content in the field. The estimated strength parameters could be used for safety evaluation and/or engineering design.

(3) With the increasing moisture content, the rate of reduction of the cohesion is much higher than that of the tangent value of frictional angle, indicating that the bonds in the undisturbed CDG are much easily influenced by the moisture content than the fabric.

\section{Data Availability}

The data used to support the findings of this study are included within the article.

\section{Disclosure}

This study was conducted as part of the employment of the authors.

\section{Conflicts of Interest}

The authors declare that there are no conflicts of interest regarding the publication of this paper.

\section{References}

[1] L.-T. Zhan, Z. Zhang, Y.-M. Chen et al., "The 2015 Shenzhen catastrophic landslide in a construction waste dump: reconstitution of dump structure and failure mechanisms via geotechnical investigations," Engineering Geology, vol. 238, pp. 15-26, 2018.

[2] I.-M. Lee, S.-G. Sung, and G.-C. Cho, "Effect of stress state on the unsaturated shear strength of a weathered granite," $\mathrm{Ca}$ nadian Geotechnical Journal, vol. 42, no. 2, pp. 624-631, 2005.

[3] Z. Hu, K. Peng, L. H. Li et al., "Effect of wetting-drying cycles on mechanical behaviour and electrical resistivity of unsaturated subgrade soil," Advances in Civil Engineering, vol. 2019, Article ID 3465327, 2019.

[4] F. N. Charkley, K. Y. Zhang, and G. X. Mei, "Shear strength of compacted clays as affected by mineral content and wet-dry cycles," Advances in Civil Engineering, vol. 2019, Article ID 8217029, 2019.

[5] P. Liu, X. J. Zhang, M. Zhang, and X. Q. Yang, "Effect of admixture on the hydraulic conductivity of compacted loess: a case study," Advances in Civil Engineering, vol. 2020, Article ID 8810079, 12 pages, 2020.

[6] B. X. Yuan, M. Sun, L. Xiong, Q. Z. Luo, S. P. Pradhan, and H. Z. Li, "Investigation of 3D deformation of transparent soil around a laterally loaded pile based on a hydraulic gradient model test," Journal of Building Engineering, vol. 28, no. 3, 9 pages, Article ID 101024, 2020.

[7] S. Zhao, T. M. Evans, and X. Zhou, "Effects of curvature-related DEM contact model on the macro-and micro-mechanical behaviours of granular soils," Géotechnique, vol. 68, no. 12, pp. 1085-1098, 2018.

[8] B. X. Yuan, M. Sun, Y. X. Wang, L. H. Zhai, Q. Z. Luo, and X. Q. Zhang, "Full 3D displacement measuring system for 3D displacement field of soil around a laterally loaded pile in transparent soil," International Journal of Geomechanics, vol. 19, no. 5, p. 8, Article ID 04019028, 2019.

[9] H. X. Lan, R. L. Hu, Z. Q. Yue, C. F. Lee, and S. J. Wang, "Engineering and geological characteristics of granite 
weathering profiles in South China," Journal of Asian Earth Sciences, vol. 21, no. 4, pp. 353-364, 2003.

[10] C. F. Chiu and C. W. W. Ng, "Relationships between chemical weathering indices and physical and mechanical properties of decomposed granite," Engineering Geology, vol. 179, pp. 7689, 2014

[11] B. Yuan, L. Xiong, L. Zhai et al., "Transparent synthetic soil and its application in modeling of soil-structure interaction using optical system," Frontiers in Earth Science, vol. 7, p. 276, 2019.

[12] L. Borana, J. H. Yin, D. N. Singh, S. K. Shukla, and F. D. Tong, "Direct shear testing study of the interface behavior between steel plate and compacted completely decomposed granite under different vertical stresses and suctions," Journal of Engineering Mechanics, vol. 144, no. 1, Article ID 04017148, 2018.

[13] C. W. W. Ng, D. B. Akinniyi, C. Zhou, and C. F. Chiu, "Comparisons of weathered lateritic, granitic and volcanic soils: compressibility and shear strength," Engineering Geology, vol. 249, pp. 235-240, 2019.

[14] M. A. Hossain and J.-H. Yin, "Behavior of a compacted completely decomposed granite soil from suction controlled direct shear tests," Journal of Geotechnical and Geoenvironmental Engineering, vol. 136, no. 1, pp. 189-198, 2010.

[15] M. A. Hossain and J.-H. Yin, "Shear strength and dilative characteristics of an unsaturated compacted completely decomposed granite soil," Canadian Geotechnical Journal, vol. 47, no. 10, pp. 1112-1126, 2010.

[16] K. K. Lu, J. H. Yin, and S. C. Lo, "Modeling small-strain behavior of Hong Kong CDG and its application to finiteelement study of basement-raft footing," International Journal of Geomechanics, vol. 18, no. 9, Article ID 04018104, 2018.

[17] Y. R. Zhao, H. Q. Yang, L. P. Huang, R. Chen, X. S. Chen, and S. Y. Liu, "Mechanical behavior of intact completely decomposed granite soils along multi-stage loading-unloading path," Engineering Geology, vol. 260, Article ID 105242, 2019.

[18] P. Liu, X. W. Zhou, and Y. B. He, "Bond yield characteristics of undisturbed completely decomposed granite," Advances in Materials and Engineering, vol. 2015, Article ID 325162, 2015.

[19] Geotechnical Engineering Office (GEO), Guide to Rock and Soil Descriptions, Geotechnical Engineering Office (GEO), Hong Kong, China, 1988.

[20] British Standards Institution (BSI), Methods of Tests for Soils for Civil Engineering Purposes, British Standards Institution (BSI), London, UK, 1990.

[21] American Society for Testing and Materials (ASTM), D248717, Standard Practice for Classification of Soils for Engineering Purposes (Unified Soil Classification System), American Society for Testing and Materials (ASTM), West Conshohocken, PA, USA, 2017. 